\title{
Relationship Between Gastroesophageal Reflux Symptoms and Dietary Factors in Korea
}

\author{
Ji Hyun Song, ${ }^{1}$ Su Jin Chung, ${ }^{1}$ Jun Haeng Lee, ${ }^{2}$ Young-Ho Kim, ${ }^{2}$ Dong Kyung Chang, ${ }^{2}$ Hee Jung Son, ${ }^{2}$ Jae J Kim, \\ Jong Chul Rhee ${ }^{2}$ and Poong-Lyul Rhee ${ }^{2 *}$ \\ ${ }^{1}$ Healthcare System Gangnam Center, Seoul National University Hospital, Healthcare Research Institute, Seoul, Korea, ${ }^{2}$ Department of Medicine, \\ Samsung Medical Center, Sungkyunkwan University School of Medicine, Seoul, Korea
}

\begin{abstract}
Background/Aims
The incidence of gastroesophageal reflux disease (GERD) is increasing in Korea. The aim of this study was to evaluate the relationship between GERD symptoms and dietary factors in Korea.
\end{abstract}

\section{Methods}

From January 2007 to April 2008, 162 subjects were enrolled (81 in GERD group and 81 in control group). They were asked to complete the questionnaires about GERD symptoms and dietary habits. The symptom severity score was recorded by visual analogue scale.

\section{Results}

Subjects with overweight or obesity had an increased risk for GERD $(O R, 2.52 ; 95 \% \mathrm{Cl}, 1.18-5.39)$. Irregular dietary intake was one of the risk factors for GERD $(O R, 2.33 ; 95 \% \mathrm{Cl}, 1.11-4.89)$. Acid regurgitation was the most suffering (2.85 \pm 2.95 by visual analogue scale) and frequent reflux-related symptom (57.5\%) in GERD. Noodles (OR, 1.22; 95\% Cl, 1.12-1.34), spicy foods (OR, 1.09; 95\% Cl, 1.02-1.16), fatty meals (OR, 1.20;95\% Cl, 1.09-1.33), sweets (OR, 1.42; 95\% Cl, 1.00-2.02), alcohol $(O R, 1.16 ; 95 \% \mathrm{Cl}, 1.03-1.31)$, breads $(\mathrm{OR}, 1.17 ; 95 \% \mathrm{Cl}, 1.01-1.34)$, carbonated drinks $(\mathrm{OR}, 1.69 ; 95 \% \mathrm{Cl}, 1.04-2.74)$ and caffeinated drinks $(O R, 1.41 ; 95 \% \mathrm{Cl}, 1.15-1.73)$ were associated with symptom aggravation in GERD. Among the investigated noodles, ramen (instant noodle) caused reflux-related symptoms most frequently (52.4\%).

\section{Conclusions}

We found that noodles, spicy foods, fatty meals, sweets, alcohol, breads, carbonated drinks and caffeinated drinks were associated with reflux-related symptoms.

\section{(J Neurogastroenterol Motil 2011;17:54-60)}

\section{Key Words}

Diet; Food habits; Gastroesophageal reflux disease; Symptom

Received: October 22, 2010 Revised: December 3, 2010 Accepted: December 11, 2010

(c) This is an Open Access article distributed under the terms of the Creative Commons Attribution Non-Commercial License (http://creativecommons. org/licenses/by-nc/3.0) which permits unrestricted non-commercial use, distribution, and reproduction in any medium, provided the original work is properly cited.

*Correspondence: Poong-Lyul Rhee, MD Department of Medicine, Samsung Medical Center, Sungkyunkwan University School of Medicine, 50 llwon-dong, Gangnam-gu, Seoul 135-710, Korea

Financial support: None.

Tel: +82-2-3410-3409, Fax: +82-2-3410-6983, E-mail: plrhee@skku.edu

Conflicts of interest: None. 


\section{Introduction}

Gastroesophageal reflux disease (GERD) is a condition which develops when the reflux of gastric contents cause troublesome symptoms and/or complications. ${ }^{1}$ A recent systematic review identified a 10\%-20\% prevalence of GERD, defined by at least weekly heartburn and/or regurgitation in the Western world; while in Asia, the prevalence was less than $5 \%{ }^{2}$ It has been suggested that there is an increasing trend in the prevalence of GERD over the last 2 decades and that reflux disease is more common in Asian countries than previously recognized. ${ }^{3}$ For the differences in prevalence rate in different countries, there are several potential explanations; such as lifestyle factors, dietary factors, overweight/ obesity and genetic factors. However, the exact pathogenetic role of these factors is still under debate and the beneficial effect of recommending specific modification in lifestyle habits is also controversial. $^{4}$

GERD is a multi-factorial disease with both environmental and genetic risk factors, and several epidemiological data lend support to this concept. ${ }^{5}$ Various lifestyle factors are thought to be associated with GERD symptoms, including body weight, nutrition, alcohol consumption, smoking, the intake of NSAIDs and sleeping position. ${ }^{6}$ There are many patients who are more likely to experience a perceived reflux event when they eat some foods like noodles. It is a common belief that some foods may induce or worsen GERD symptoms. In fact, in daily clinical practice, this belief leads to advising patients to avoid the suspected foods. ${ }^{7}$ Furthermore, since GERD symptoms are most commonly reported postprandially, the role of dietary components in inducing symptoms has been suggested. ${ }^{7}$ However, no definitive data exist regarding the role of diet and specific foods or drinks in influencing on GERD symptoms. ${ }^{7}$ The aim of this study was to evaluate the relationship between GERD symptoms and dietary factors, especially regular meals in Korea.

\section{Materials and Methods}

\section{Subjects}

From January 2007 to April 2008, patients attending department of medicine in Samsung Medical Center with frequent (more than weekly) typical reflux symptoms such as acid regurgitation or heartburn were recruited as GERD group. All of these patients underwent esophagogastroduodenoscopy (EGD) to confirm erosive esophagitis or other combined disorder. In case of erosive reflux disease, the severity of erosive esophagitis seen on EGD was graded from A to D according to the Los Angeles (LA) classification. ${ }^{8}$ In the same period, randomly selected subjects attending Seoul National University Hospital Healthcare System Gangnam Center for routine health check-up to be confirmed without erosive esophagitis or hiatal hernia by EGD were recruited as control group. Subjects with typical reflux symptoms more than once a week within the last 1 year were excluded in control group.

Subjects were excluded if they have other gastrointestinal diseases (for example, active peptic ulcer disease, infectious conditions of the intestine and gastric malignancy), a history of gastrectomy or severe health problems. Exclusion criteria also contained the subjects who require daily use of NSAIDs, oral steroid or aspirin, on proton pump inhibitors or histamine-2 receptor antagonists over the preceding 4 weeks, and currently pregnant women.

The participants were asked to complete the questionnaires consisted of questions about the patient's demographics, reflux related symptoms and diet factors. Body mass index was calculated as a ratio between weight $(\mathrm{kg})$ and the square of height $\left(\mathrm{m}^{2}\right)$ and further categorized as follows based on recommended cutoffs: normal $(<23)$, overweight or obesity $(\geq 23)$. A total of 162 subjects ( 81 in GERD group and 81 in control group) agreed to complete the questionnaire and were enrolled in this study. Written informed consents were obtained from all participants. This study received approval from the institutional review board of the Samsung Medical Center and Seoul National University Hospital.

\section{Questionnaire}

The questionnaire consisted of the following questions:

(1) Questions about dietary habits (large-volume meal, rapid food intake, irregular intake, eating between meals and late-evening meal)
A. How much do you take each meal?
B. How long does it take to eat a regular meal?
C. Do you eat regularly?
D. Do you eat between meals?
E. Do you eat in late evening or at night?

(2) Do you suffer from the following symptoms? How often? How severe are the symptoms? (recorded by visual analogue scale [VAS])
A. Heartburn 

B. Acid regurgitation
C. Chest discomfort
D. Chest pain
E. Hoarseness
F. Globus sensation
G. Cough
H. Epigastric pain
I. Epigastric soreness
J. dyspepsia

(3) How long do you suffer from the symptoms?

(4) Did you feel the symptom development or aggravation after eating specific food? What was(were) the food(s)? And how severe were the symptoms? (recorded by VAS)

\section{Diet factors}

The questionnaires also asked whether they suffered from reflux-related symptoms with specific food intake. The foods possibly causing reflux-related symptoms were listed in Korean's favorite foods extracted from the Third Korea National Health \& Nutrition Examination Survey (KNHANES III). ${ }^{9}$

\section{Symptom assessment}

The severities of reflux related symptoms (heartburn, acid regurgitation, chest discomfort, chest pain, hoarseness, globus sensation, cough, epigastric pain, epigastric soreness and dyspepsia) ${ }^{10}$ were recorded by $10 \mathrm{~cm}$ VAS running from 0 (no symptom) to 10 (maximal symptom expression).

\section{Statistical Methods}

Statistic analysis was performed using the Student's $t$ test and Chi-square to compare the differences between the 2 groups. Multivariate logistic regression models were used to assess the

Table 1. Clinical Characteristics

\begin{tabular}{lccr}
\hline & GERD $(\mathrm{n}=81)$ & Contol $(\mathrm{n}=81)$ & $P$-value \\
\hline $\begin{array}{l}\text { Age }(\mathrm{yr}) \\
\text { Sex }\end{array}$ & $57.31 \pm 9.73$ & $50.23 \pm 11.33<0.001$ \\
$\quad$ Male & $60(74.1 \%)$ & $46(56.8 \%)$ & 0.016 \\
$\quad$ Female & $21(25.9 \%)$ & $35(43.2 \%)$ & \\
Height $(\mathrm{cm})$ & $166.15 \pm 7.40$ & $164.28 \pm 7.99$ & 0.132 \\
Weight $(\mathrm{kg})$ & $67.32 \pm 9.57$ & $63.78 \pm 11.76$ & 0.042 \\
BMI $\left(\mathrm{kg} / \mathrm{m}^{2}\right)$ & & & 0.002 \\
$\quad$ Overweight or obese & $57(76.0 \%)$ & $41(51.9 \%)$ & \\
$\quad(\geq 23)$ & & & \\
$\quad$ Normal $(<23)$ & $18(24.0 \%)$ & $38(48.1 \%)$ & \\
\hline
\end{tabular}

GERD, gastroesophageal reflux disease; BMI, body mass index. Continuous variables are presented as the mean $\pm \mathrm{SD}$ and noncontinuous variables as the number $(\%)$. potential risk factors of GERD. Age- and sex-adjusted data of dietary habits, reflux-related symptoms and specific foods were also analyzed by multiple logistic regression. All $P$-values were 2-tailed, and $P$-values of less than 0.05 were considered statistically significant.

\section{Results}

The clinical characteristics of the study subjects are presented in Table 1. Mean ages were 57 years in GERD group and 50 years in control group $(P<0.001)$. Subjects with overweight or obesity had an increased risk for GERD (OR, 2.52; 95\% CI, 1.18-5.39) (Table 2). In GERD group, endoscopic findings were as follows; 13 patients $(16.0 \%)$ had non-erosive reflux disease, 30 patients (37.0\%) were LA-A, 34 patients $(42.0 \%)$ were LA-B and 4 patients $(5.0 \%)$ were LA-C. In our study population, there was no patient with LA-D.

Table 3 shows the relationship between dietary habits and GERD. The odds ratio of irregular dietary intake was 2.33 (95\% CI, 1.11-4.89), but other habits (large-volume meal, rapid food intake, eating between meals and late-evening meals) did not show statistical significance. Table 4 shows the comparison of dietary habits according to the endoscopic severity of GERD. Largevolume meal was significantly associated with the grade of erosive

Table 2. Multivariate Analysis of Risk Factors for Gastroesophageal Reflux Disease

\begin{tabular}{lccc}
\hline & OR & $95 \%$ CI & $P$-value \\
\hline $\begin{array}{l}\text { Age }(\mathrm{yr}) \\
\text { Sex }\end{array} \quad 1.07$ & $1.03-1.11$ & $<0.001$ \\
$\quad$ Male & & & \\
$\quad$ Female & 1.60 & $0.74-3.43$ & 0.225 \\
BMI $\left(\mathrm{kg} / \mathrm{m}^{2}\right)$ & Reference & & \\
$\quad$ Overweight or obese $(\geq 23)$ & 2.52 & $1.18-5.39$ & 0.017 \\
$\quad$ Normal $(<23)$ & Reference & & \\
\hline BMI, body mass index. & & &
\end{tabular}

Table 3. Relationship Between Dietary Habits and Gastroesophageal Reflux Disease

\begin{tabular}{lccc}
\hline & OR & $95 \% \mathrm{CI}$ & $P$-value \\
\hline Large-volume meal & 2.09 & $0.54-8.03$ & 0.285 \\
Rapid intake $(\leq 10 \mathrm{~min})$ & 0.75 & $0.39-1.45$ & 0.392 \\
Irregular intake & 2.33 & $1.11-4.89$ & 0.026 \\
Eating between meals & 1.07 & $0.53-2.19$ & 0.845 \\
Late-evening meals & 2.58 & $0.77-8.66$ & 0.125 \\
\hline
\end{tabular}

It was adjusted for age and sex. 
Table 4. The Comparison of Dietary Habits According to the Endoscopic Severity of Gastroesophageal Reflux Disease

\begin{tabular}{|c|c|c|c|c|c|}
\hline & NERD & LA-A & LA-B & LA-C & $P$-value \\
\hline Large-volume meal & & & & & 0.021 \\
\hline Yes & $1(7.7)$ & $1(3.3)$ & $3(8.8)$ & $2(50.0)$ & \\
\hline No & $12(92.3)$ & $29(96.7)$ & $31(91.2)$ & $2(50.0)$ & \\
\hline Rapid intake $(\leq 10 \mathrm{~min})$ & & & & & 0.808 \\
\hline Yes & $6(46.2)$ & $15(50.0)$ & $13(38.2)$ & $2(50.0)$ & \\
\hline No & $7(53.8)$ & $15(50.0)$ & $21(61.8)$ & $2(50.0)$ & \\
\hline Irregular intake & & & & & 0.225 \\
\hline Yes & $3(23.1)$ & $10(33.3)$ & $15(44.1)$ & $3(75.0)$ & \\
\hline No & $10(76.9)$ & $20(66.7)$ & $19(55.9)$ & $1(25.0)$ & \\
\hline Eating between meals & & & & & 0.446 \\
\hline Yes & $8(61.5)$ & $18(60.0)$ & $23(67.6)$ & $4(100.0)$ & \\
\hline No & $5(38.5)$ & $12(40.0)$ & $11(32.4)$ & $0(0.0)$ & \\
\hline Late-evening meals & & & & & 0.851 \\
\hline Yes & $2(15.4)$ & $3(10.0)$ & $4(11.8)$ & $0(0.0)$ & \\
\hline No & $11(84.6)$ & $27(90.0)$ & $30(88.2)$ & $4(100.0)$ & \\
\hline
\end{tabular}

NERD, non-erosive reflux disease; LA-A, Los Angeles classification A; LA-B, Los Angeles classification B; LA-C, Los Angeles classification C. Data are presented as the number $(\%)$.

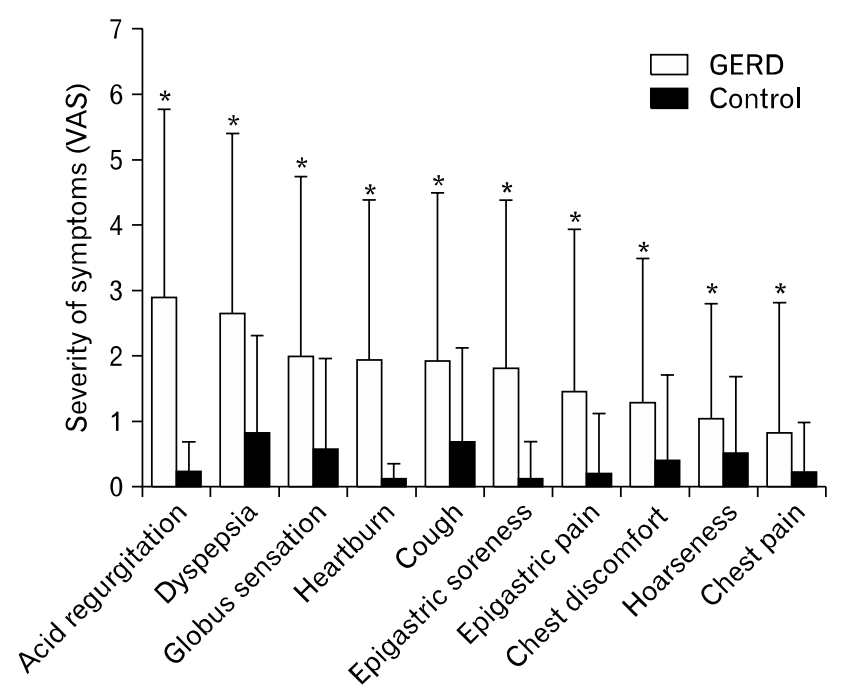

Figure 1. The severity of symptoms related with reflux. The severities of symptoms were measured by visual analogue scale. Acid regurgitation was the most suffering reflux related symptom in gastroesophageal reflux disease $(* P<0.05)$. GERD, gastroesophageal reflux disease; VAS, visual analogue scale.

esophagitis.

Each reflux-related symptom was assessed by severity and frequency. The severity of symptoms measured by VAS is shown in Figure 1. In GERD group, acid regurgitation was the most suffering symptom $(2.85 \pm 2.95)$, whereas dyspepsia was the most suffering symptom $(0.76 \pm 1.57)$ in control group. When
Table 5. The Relationship Between Reflux Related Symptoms and Gastroesophageal Reflux Disease

\begin{tabular}{lccr}
\hline & OR & $95 \% \mathrm{CI}$ & $P$-value \\
\hline Heartburn & 4.30 & $1.86-9.97$ & 0.001 \\
Acid regurgitation & 4.31 & $2.35-7.90$ & $<0.001$ \\
Chest discomfort & 1.47 & $1.13-1.92$ & 0.004 \\
Chest pain & 1.39 & $1.01-1.92$ & 0.045 \\
Hoarseness & 1.29 & $1.00-1.67$ & 0.047 \\
Globus sensation & 1.46 & $1.19-1.80$ & $<0.001$ \\
Cough & 1.42 & $1.16-1.73$ & 0.001 \\
Epigastric pain & 1.98 & $1.32-2.98$ & 0.001 \\
Epigastric soreness & 2.86 & $1.66-4.94$ & $<0.001$ \\
Dyspepsia & 1.62 & $1.32-1.99$ & $<0.001$ \\
\hline
\end{tabular}

It was adjusted for age and sex.

the data were adjusted for age and sex, the most highly associated symptoms with GERD were acid regurgitation (OR, 4.31; 95\% $\mathrm{CI}, 2.35-7.90)$ and heartburn (OR, 4.30; 95\% CI, 1.86-9.97) (Table 5). Acid regurgitation was the most frequent symptom in GERD group (57.5\%), whereas cough was most frequent in control group (16.0\%).

Figure 2 demonstrates several foods and their symptom severity scores in each group. Symptom severity scores were calculated by the sum of each severity (VAS scale) of symptoms. Noodles showed the highest symptom severity score in GERD group, and they were significantly higher than control group. When the 


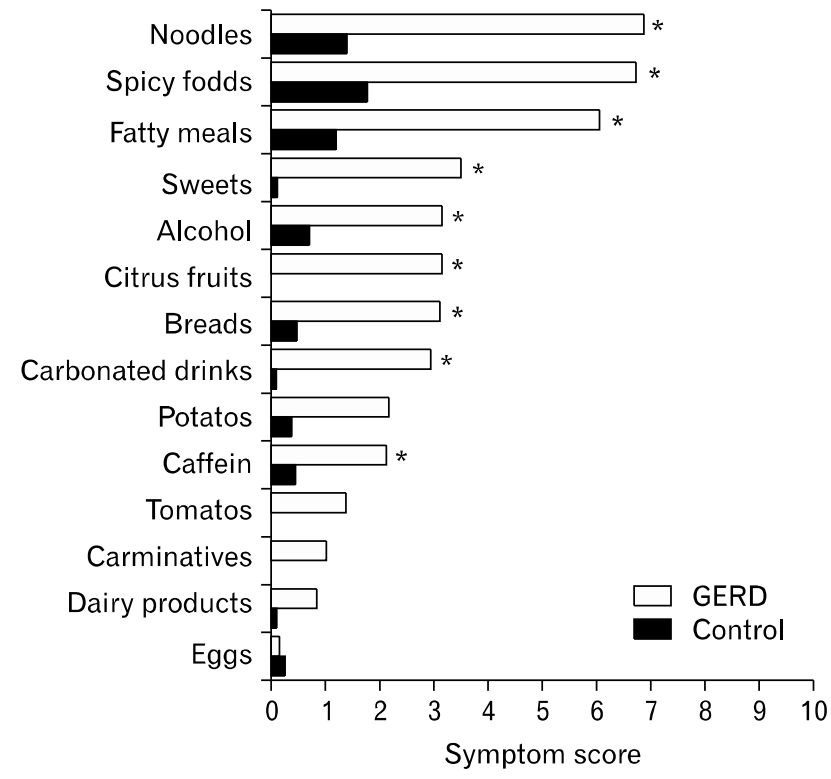

Figure 2. The specific foods and their symptom severity scores in gastroesophageal reflux disease (GERD) and control groups. Noodles, spicy foods, fatty meals, sweets, alcohol, citrus fruits, breads, carbonated drinks and caffeinated drinks were associated with significantly higher symptom severity score in GERD group $\left({ }^{*} P<0.05\right)$.

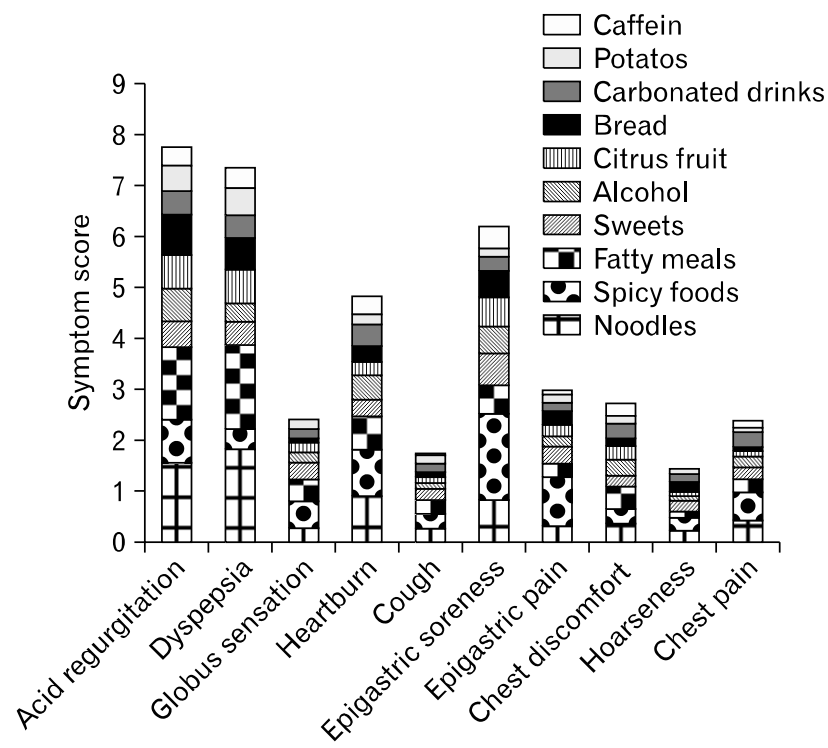

Figure 3. Relationship between reflux-related symptoms and symptom severity scores aggravated by several foods in gastroesophageal reflux disease. The symptoms of acid regurgitation, dyspepsia, epigastric soreness and heartburn were more aggravated by these foods.

data were adjusted for age and sex, noodles (OR, 1.22; 95\% CI, $1.12-1.34)$, spicy foods (OR, 1.09; 95\% CI, 1.02-1.16), fatty meals (OR, 1.20; 95\% CI, 1.09-1.33), sweets (OR, 1.42; 95\%
Table 6. The Relationship Between Specific Foods and Symptom Aggravation in Gastroesophageal Reflux Disease

\begin{tabular}{lrlr}
\hline & OR & $95 \%$ CI & $P$-value \\
\hline Noodles & 1.22 & $1.12-1.34$ & $<0.001$ \\
Spicy foods & 1.09 & $1.02-1.16$ & 0.014 \\
Fatty meals & 1.20 & $1.09-1.33$ & $<0.001$ \\
Sweets & 1.42 & $1.00-2.02$ & 0.048 \\
Alcohol & 1.16 & $1.03-1.31$ & 0.019 \\
Citrus fruits & 10.26 & $0.82-128.24$ & 0.071 \\
Breads & 1.17 & $1.01-1.34$ & 0.034 \\
Carbonated drinks & 1.69 & $1.04-2.74$ & 0.035 \\
Caffeinated drinks & 1.41 & $1.15-1.73$ & 0.001 \\
\hline
\end{tabular}

It was adjusted for age and sex.

Table 7. The List of Noodles Causing Symptoms: Patients With Symptom Aggravation by Noodles Reported Which Kind Did by Multiple Choice

\begin{tabular}{|c|c|c|c|}
\hline Noodles & No & $\begin{array}{c}\% \text { of } \\
\text { responses }\end{array}$ & $\begin{array}{l}\% \text { of } \\
\text { cases }\end{array}$ \\
\hline Ramen (instant noodles) & 22 & 22.9 & 52.4 \\
\hline Noodles with stir-fried bean paste & 15 & 15.6 & 35.7 \\
\hline Noodles with Chinese-style hotchpotch & 14 & 14.6 & 33.3 \\
\hline Clear soup with wheat flakes & 10 & 10.4 & 23.8 \\
\hline Handmade knife-cut noodles & 9 & 9.4 & 21.4 \\
\hline Spaghetti & 8 & 8.3 & 19.0 \\
\hline Bi bim naeng myun ${ }^{a}$ & 7 & 7.3 & 16.7 \\
\hline Udon & 5 & 5.2 & 11.9 \\
\hline Mool naeng myun ${ }^{\mathrm{b}}$ & 3 & 3.1 & 7.1 \\
\hline Plain noodles & 2 & 2.1 & 4.8 \\
\hline Buckwheat noodles & 1 & 1.0 & 2.4 \\
\hline
\end{tabular}

${ }^{a}$ Cold noodles served with hot and spicy sauce mix, ${ }^{b}$ Cold noodles served in cold beef soup.

CI, 1.00-2.02), alcohol (OR, 1.16; 95\% CI, 1.03-1.31), breads (OR, 1.17; 95\% CI, 1.01-1.34), carbonated drinks (OR, 1.69; 95\% CI, 1.04-2.74) and caffeinated drinks (OR, 1.41; 95\% CI, $1.15-1.74)$ were associated with symptom aggravation in GERD (Table 6).

The subjects who answered that reflux related symptoms developed or were aggravated by noodles were asked what kinds of noodles contributed to the symptom. More than half of the responders answered that ramen (instant noodle) caused reflux-related symptoms (Table 7).

The relationship between reflux-related symptoms and symptom severity scores aggravated by several foods in GERD is shown in Figure 3. The symptoms of acid regurgitation, dyspep- 
sia, epigastric soreness and heartburn were more aggravated by these foods.

\section{Discussion}

The most common symptom in GERD patients is heartburn in Western countries. ${ }^{11}$ Several studies have reported the prevalence of heartburn as $21 \%-37 \%$ to experience heartburn at least once a month and as $13 \%-25 \%$ to experience at least once a week or more frequently. ${ }^{12-14}$ In this study, however, the most frequent and bothersome symptom of GERD patients was acid regurgitation. This may be attributed to cultural and linguistic differences in symptom perception and interpretation. The term "heartburn" is not universally understood and there is no direct translation of the word "heartburn" in Chinese, Swedish, Malay or Korean. ${ }^{3}$ A multiethnic study showed that the term "heartburn" was understood by only $35 \%$ of white American subjects and the figure dropped to $13 \%$ for Asian patients. ${ }^{15}$

The present study showed that subjects with overweight or obesity had an increased risk for GERD. These results are in agreement with those of previous studies which reported that body mass index may be associated with symptomatic gastroesophageal reflux, independent of diet and exercise. ${ }^{16,17}$

It is a common belief that some dietary habits would aggravate GERD-related symptoms, such as large-volume meal, rapid food intake, irregular food intake, eating between meals or lateevening meals. Physicians often advise patients with GERD to change their dietary habit and lifestyle. However, the evidence to support such recommendations of lifestyle modification has not been well substantiated. In several studies investigating the effect of dietary habits on gastroesophageal reflux, the results have not been consistent. ${ }^{18-22}$ In our study, the odds ratio for relative risk of irregular dietary intake was 2.33, while other habits (large-volume meal, rapid food intake, eating between meals and late-evening meals) did not show statistical significance. The reasons for these results might be considered in that the proportion of severe erosive esophagitis was too small in this study population. In Korea, however, the distribution of erosive esophagitis based on the LA classification is quite different from other countries. Severe esophagitis such as LA-C or LA-D accounts for only $3 \%$ in Korea, ${ }^{23}$ which is the reason why our study population was so deviated.

In this study, we showed that noodles induced severe symptom aggravation in GERD group. Noodles are one of the most favorite meals in Korea. To our knowledge, this is the first study to suggest that noodles may be refluxogenic to GERD patients. A possible explanation is the high carbohydrate content of noodles. A recent study showed that very low-carbohydrate diet in individuals with GERD significantly reduces distal esophageal acid exposure and improves symptoms. ${ }^{24} \mathrm{~A}$ second explanation for our findings is that noodles are generally made by wheat, which is more likely to precipitate the reflux related symptoms than rice. ${ }^{25}$ Other possible explanation is the high salt intake. It has been demonstrated that salt intake seems to be a risk factor for reflux symptoms. ${ }^{26}$ In our results, the most "refluxogenic" noodles, such as ramen and noodles with stir-fried bean paste, contain high salt content.

We also found that reflux-related symptoms were associated with spicy foods, fatty meals, sweets, alcohol, carbonated drinks and caffeinated drinks. These results are consistent with several physiological studies which have shown a decrease in lower esophageal pressure and an increase in esophageal acid exposure in response to ingestion of a variety of food items. ${ }^{27-29}$

There are several limitations that should be acknowledged. First, unmatched control group with ambiguous criteria may have resulted in a selection bias. The second limitation of this study was a relatively small number of subjects.

In summary, subjects with overweight or obesity had an increased risk for GERD. Irregular dietary intake was one of the risk factors for GERD. Acid regurgitation was the most suffering and most frequent reflux-related symptom in GERD. Noodles, spicy foods, fatty meals, sweets, alcohol, breads, carbonated drinks and caffeinated drinks were associated with symptom aggravation in GERD. Among the investigated noodles, ramen caused reflux-related symptoms most frequently.

In conclusion, this is the first study in Korea to suggest that noodles may be refluxogenic to GERD patients. Large prospective controlled trials are warranted to recommend more precise dietary and lifestyle modifications in the treatment of GERD.

\section{References}

1. Vakil N, van Zanten SV, Kahrilas P, Dent J, Jones R; Global Consensus Group. The Montreal definition and classification of gastroesophageal reflux disease: a global evidence-based consensus. Am J Gastroenterol 2006;101:1900-1920.

2. Dent J, El-Serag HB, Wallander MA, Johansson S. Epidemiology of gastro-oesophageal reflux disease: a systematic review. Gut 2005; 54:710-717.

3. Sharma P, Wani S, Romero Y, Johnson D, Hamilton F. Racial and geographic issues in gastroesophageal reflux disease. Am J Gastroenterol 2008;103:2669-2680. 
4. Kaltenbach T, Crockett S, Gerson LB. Are lifestyle measures effective in patients with gastroesophageal reflux disease? An evidencebased approach. Arch Intern Med 2006;166:965-971.

5. Belhocine K, Galmiche JP. Epidemiology of the complications of gastroesophageal reflux disease. Dig Dis 2009;27:7-13.

6. Nocon M, Labenz J, Willich SN. Lifestyle factors and symptoms of gastro-oesophageal reflux - a population-based study. Aliment Pharmacol Ther 2006;23:169-174.

7. Festi D, Scaioli E, Baldi F, et al. Body weight, lifestyle, dietary habits and gastroesophageal reflux disease. World J Gastroenterol 2009;15: 1690-1701.

8. Armstrong D, Bennett JR, Blum AL, et al. The endoscopic assessment of esophagitis: a progress report on observer agreement. Gastroenterology 1996;111:85-92.

9. The Third Korea National Health \& Nutrition Examination Survey (KNHANES III), 2005 - Nutrition survey (1): Ministry of Health and Welfare, Korea Health Industry Development Institute, 2006.

10. Hwang JK, Kim J, Hong SG, et al. [A prospective multicenter study on the prevalence and symptoms of erosive reflux esophagitis in secondary and tertiary hospitals in Korea.] Korean J Gastroenterol 2009;53:283-291. [Korean]

11. Rothman M, Farup C, Stewart W, Helbers L, Zeldis J. Symptoms associated with gastroesophageal reflux disease: development of a questionnaire for use in clinical trials. Dig Dis Sci 2001;46:15401549.

12. Talley NJ, Zinsmeister AR, Schleck CD, Melton LJ 3rd. Dyspepsia and dyspepsia subgroups: a population-based study. Gastroenterology 1992;102:1259-1268.

13. El-Serag HB, Petersen NJ, Carter J, et al. Gastroesophageal reflux among different racial groups in the United States. Gastroenterology 2004;126:1692-1699.

14. Mohammed I, Nightingale P, Trudgill NJ. Risk factors for gastrooesophageal reflux disease symptoms: a community study. Aliment Pharmacol Ther 2005;21:821-827.

15. Spechler SJ, Jain SK, Tendler DA, Parker RA. Racial differences in the frequency of symptoms and complications of gastro-oesophageal reflux disease. Aliment Pharmacol Ther 2002;16:1795-1800.

16. El-Serag HB, Graham DY, Satia JA, Rabeneck L. Obesity is an independent risk factor for GERD symptoms and erosive esophagitis. Am J Gastroenterol 2005;100:1243-1250.

17. Nandurkar S, Locke GR 3rd, Fett S, Zinsmeister AR, Cameron AJ,
Talley NJ. Relationship between body mass index, diet, exercise and gastro-oesophageal reflux symptoms in a community. Aliment Pharmacol Ther 2004;20:497-505.

18. Iwakiri K, Kobayashi M, Kotoyori M, Yamada H, Sugiura T, Nakagawa Y. Relationship between postprandial esophageal acid exposure and meal volume and fat content. Dig Dis Sci 1996;41:926-930.

19. Dore MP, Maragkoudakis E, Fraley K, et al. Diet, lifestyle and gender in gastro-esophageal reflux disease. Dig Dis Sci 2008;53:20272032.

20. Orr WC, Harnish MJ. Sleep-related gastro-oesophageal reflux: provocation with a late evening meal and treatment with acid suppression. Aliment Pharmacol Ther 1998;12:1033-1038.

21. Fujiwara $Y$, Machida A, Watanabe $Y$, et al. Association between dinner-to-bed time and gastro-esophageal reflux disease. Am J Gastroenterol 2005;100:2633-2636.

22. Wildi SM, Tutuian R, Castell DO. The influence of rapid food intake on postprandial reflux: studies in healthy volunteers. Am J Gastroenterol 2004;99:1645-1651.

23. Kim N, Lee SW, Cho SI, et al. The prevalence of and risk factors for erosive oesophagitis and non-erosive reflux disease: a nationwide multicentre prospective study in Korea. Aliment Pharmacol Ther 2008;27:173-185

24. Austin GL, Thiny MT, Westman EC, Yancy WS Jr, Shaheen NJ. A very low-carbohydrate diet improves gastroesophageal reflux and its symptoms. Dig Dis Sci 2006;51:1307-1312.

25. Sohn SM, Song CW, Koo JS, et al. [Gastroesophageal acid reflux according to different meals: flour cake vs rice cake.] Korean J Gastrointest Motil 2001;7:181-187. [Korean]

26. Nilsson M, Johnsen R, Ye W, Hveem K, Lagergren J. Lifestyle related risk factors in the aetiology of gastro-oesophageal reflux. Gut 2004;53:1730-1735.

27. Becker DJ, Sinclair J, Castell DO, Wu WC. A comparison of high and low fat meals on postprandial esophageal acid exposure. Am J Gastroenterol 1989;84:782-786.

28. Hamoui N, Lord RV, Hagen JA, Theisen J, Demeester TR, Crookes PF. Response of the lower esophageal sphincter to gastric distention by carbonated beverages. J Gastrointest Surg 2006;10:870877.

29. Murphy DW, Castell DO. Chocolate and heartburn: evidence of increased esophageal acid exposure after chocolate ingestion. Am J Gastroenterol 1988;83:633-636. 